\title{
PREDICTORS OF GENITOURINARY SYNDROME IN WOMEN OF ELDERLY REPRODUCTIVE AGE AFTER HYSTERECTOMY
}

\author{
Olha Proshchenko, Iryna Ventskivska, Natalia Kamuz, Svitlana Markitanyuk
}

The article presents an analytical assessment of risk factors for distant postoperative urogenital disorders in women of older reproductive age after radical surgical treatment for uterine fibroids.

The aim of the study was to optimize the diagnostic algorithm of genitourinary syndrome in women of older reproductive age after hysterectomy for uterine fibroids.

Materials and methods - 80 women aged 40 to 50 years were examined: 40 patients after vaginal and laparoscopically assisted vaginal hysterectomy, 40 patients with abdominal hysterectomy, control - 30 relatively healthy women with asymptomatic fibroids. The examination was performed at the stage of preoperative observation and for 3 years after surgery. Research methods: data on the assessment of pelvic floor and urogenital dysfunction using a standardized $P O P-Q$ system, physical examination, the ICS classification was used to assess the severity of urinary incontinence; quality of life assessment using the MOS SF-36 questionnaire; standard methods of variation statistics.

Research results and their discussion. The most important risk factors for genitourinary syndrome have been identified. These included obstetric and gynecological history (birth of large fetuses, episiotomies, birth trauma, high birth parity, ovarian surgery, the use of gonadotropin-releasing hormone agonists), chronic diseases accompanied by increased intramuscularly; the presence of stigmas of undifferentiated connective tissue dysplasia; clinical manifestations of pelvic floor failure and functional disorders of the urethral sphincter.

Conclusions. In the case of surgical treatment of uterine fibroids, it is advisable to take into account not only the presence of vaginal prolapse and initial dysuric manifestations, but also their predictors in the preoperative stage of the examination, as this may affect the choice of method and access in the case of surgical treatment of uterine fibroids. rehabilitation program and will obtain the expected effect of surgical recovery

Keywords: uterine fibroids, hysterectomy, pelvic floor, genitourinary syndrome

How to Cite:

Proshchenko, O., Ventskivska, I., Kamuz, N., Markitanyuk, S. (2021). Predictors of genitourinary syndrome in women of elderly reproductive age after hysterectomy. ScienceRise: Medical Science, 2 (41), 10-13. doi: http://doi.org/10.15587/2519-4798.2021.228295

(C) The Author(s) 2021

This is an open access article under the CC BY license (http://creativecommons.org/licenses/by/4.0).

\section{Introduction}

The definition of "genitourinary syndrome" includes a range of manifestations most likely associated with the development of atrophic and dystrophic processes in estrogen-dependent tissues and structures of the lower third of the urogenital tract (lower third of the ureters, bladder, urethra, vagina), as well as in the ligament of the pelvis and pelvic floor muscles $[1,2]$. The urgency of this issue is undoubtedly related to the increase in the percentage of such manifestations, the rejuvenation of this condition, and, as a consequence, a significant impact on the quality of life of women. Hysterectomy increases the risk of genitourinary syndrome. At the present stage of development of gynecology, views on this operation have changed significantly, and hysterectomy and its consequences for the impact on somatic and psychological status associated with postoperative acute circulatory ischemia of ovarian tissue are the subject of scientific exchange of many panels. Hysterectomy for uterine fibroids is characterized by hypoestrogenic status, as the uterus with fibroids is a site of local hypoestrodiolemia, and the simultaneous removal of this depot, even with the preservation of ovarian tissue inevitably leads to disruption of steroid homeostasis [3, 4]. Estrogens are neurotransmitters of the neuromuscular system of the vagina due to the high sensitivity of noradrenergic neurons, which are mainly localized in the vaginal fornices and are involved in maintaining the tone of the smooth muscles of the uterus, vagina and urethra. Estrogen deficiency can be a factor in the atony of the vaginal walls and lead to their omission $[5,6]$. In addition, against the background of hypoestrogen cells of the multilayered squamous epithelium of the vagina decrease in size, and the intermediate layer reduces the ability to synthesize glycogen, as its amount in the vaginal epithelium is regulated by estradiol. Glycogen is involved in maintaining the acidity of the vagina. Glycogen deficiency leads to anatomical and physiological insufficiency of the vaginal mucosa, reducing the number of lactobacilli and raising the $\mathrm{pH}$ level. This position is also confirmed by the fact that the neurovegetative and vasomotor components of post-hysterectomy syndrome tend to improve even without specific hormone therapy, while the symptoms of genitourinary syndrome persist and progress over time [6, 7]. 
It should be noted that the search for diagnostic predictors of urogenital disorders in the preoperative stage, timely diagnosis, development and use of surgical methods for prevention and correction of urogenital disorders in the postoperative period, expanding the introduction of modern high-tech methods of treatment of genital pathology.

The aim of this study is to optimize the diagnostic algorithm of genitourinary syndrome in women of older reproductive age after hysterectomy for uterine fibroids.

\section{Materials and methods of the research}

In the period from 2015 to 2020,80 women with symptomatic uterine fibroids who underwent hysterectomy were examined on the basis of the gynecological department of the "Kyiv Perinatal Center", the period after the operation was 3 years divided into the following groups. The main group included 40 patients aged $45.9 \pm 1.3$ years who underwent vaginal hysterectomy without appendages and laparoscopically assisted vaginal hysterectomy, the comparison group consisted of $40 \mathrm{pa}-$ tients with hysterectomy performed by abdominal access with an average age of $47.2 \pm 1.6$ years. The mean age of patients in both the main and comparison groups had no statistically significant differences compared with controls $p<0.05$. Exclusion criteria were: history of ovariectomy, malignancies of any location, severe somatic pathology, refusal of patients to participate in the study. The control group consisted of 30 women with asymptomatic fibroids of reproductive age $44.7 \pm 1.3$ years.

All questions regarding the possibility of conducting these studies were agreed with the Commission on Bioethical Expertise and Ethics of Scientific Research of the "National Medical University named after O. O. Bogomolets", protocol No. 140 dated 21.12.2020, the study was performed with the analysis of medical records before surgical recovery retrospectively, all patients gave their voluntary consent to examination, questionnaires.

The examination was performed both at the stage of preoperative observation and for 3 years after surgery. The research methods: physical examination of patients, assessment of pelvic floor condition (cough test, Valsalva test, "stoptest" probe with Kegel cones), diagnosis of urogenital dysfunction using a standardized POP-Q system; the International Continence Society (ICS) classification was used to assess the severity of urinary incontinence; assessment of the patient's quality of life using the international standard questionnaire MOS SF-36; determination of vaginal $\mathrm{pH}$ by using CITOLAB $\mathrm{pH}$ test strips. The strip was inserted into the vagina with forceps. The principle of the method is based on the absorption of the sample on the paper part by chemical reagents (methylene red and bromothymol blue) and the corresponding color change. The result was compared with the corresponding $\mathrm{pH}$ value on the color scale indicated on the strip.

Statistical processing of the results was performed using statistical packages IBM SPSS Statistics (ver. 21) and statistical environment R (ver. 3.1). Assessment of variability of indicators was performed by methods of variation statistics. For comparative analysis, we used the methods of nonparametric statistics - the Chi-square criterion $\left(\chi^{2}\right)$ and used Fisher's exact criterion.

\section{Research results}

In the process of analysis of anamnestic data, the most important risk factors were identified, taking into account their impact on the postoperative period, which may allow the formation of groups of patients who require individualized approaches in choosing surgical techniques and rehabilitation program. Thus, among the data of obstetric and gynecological history: birth of large fetuses $(20-50.0 \pm 8.0 \%, p<0.05$ and $12-30.0 \pm 3.0 \%)$, $1.5 \mathrm{~g}$ more often than in the control group $(4-13.3 \pm 6.0 \%)$, and, probably, the higher frequency of carrying out episiotomies in childbirth $(18-45.0 \pm 70.0 \%, p<0,05$ and $9-22.5 \pm 7.0 \%)$ in comparison with control $(6-20.0 \pm 7.0 \%)$, and, accordingly, a high level of maternal birth trauma $(22-55.0 \pm 8.0 \%, p<0.05$ and $16-40.0 \pm 8.0 \%, \quad p<0.05)$ compared with control (2 - 6.7 \pm 5 . \%), high parity of vaginal birth $(11-27.5 \pm 7.0 \%$, and $5-12.5 \pm 5.0 \%)$ compared with the control $(3-10.0 \pm 6.0 \%)$, surgical treatment of ovarian cysts $(3-7.5 \pm 4.0 \%$, and $2-5.0 \pm 3.0 \%)$ compared with control $(1-3.3 \pm 3.0 \%)$, the use of gonadotropinreleasing hormone agonists $(7-17.5 \pm 6.0 \%$, and $10-25.0 \pm 7.0 \%)$ compared with control $(1-3.3 \pm 3.0 \%)$. However, statistically significant differences are not observed in women with surgical treatment of ovarian cysts, the use of hormonal treatment of fibroids, high parity of vaginal delivery compared with the control group. At least one of the indirect markers of undifferentiated connective tissue dysplasia (mitral valve prolapse, predisposition to dislocation, history of fractures, varicose veins of the lower extremities, etc.) was detected in 25 cases of operatively healed $(31.3 \pm 5.0 \%)$. It should be noted that intraoperatively in $11(13.8 \pm 4.0 \%)$ of these women there was weakness of the uterine ligaments, flattening or weak expression of the sacroiliac ligaments, differences in their legs. Characterizing the dynamics of changes in the mean age of onset of the above symptoms depending on the severity of undifferentiated connective tissue dysplasia, it was found that the appearance of signs of pelvic floor descent in preparation for surgery is negatively correlated with a woman's age $(r=-0.34, p=0.005)$, and positively with the share of indirect signs of undifferentiated connective tissue dysplasia $(r=0.42, p=0.005)$, i.e. the more pronounced manifestations of undifferentiated connective tissue dysplasia, the faster this complication correlates after hysterectomy.

A survey of life quality in $23(57.5 \pm 8.0 \%)$ patients after vaginal hysterectomy and $25(62.5 \pm 8.0 \%)$ ones after abdominal hysterectomy revealed the full effectiveness of surgical recovery and improvement of quality of life one year after surgery. In $15(37.5 \pm 8.0 \%)$ patients of the main group and $12-30.0 \pm 7.0 \%$ of the comparison group there was an improvement, but at the same time dissatisfaction with the quality of life: in $10-12.5 \pm 4.0 \%(6-15.0 \pm 6.0 \%$, and $4-10.0 \pm 5.0 \%$, respectively) - due to apical prolapse, in $27-33.8 \pm 5.0 \%$ $(15-37.5 \pm 8.0 \%$, and $12-30.0 \pm 8.0 \%$, respectively) due to the accession of dysuric manifestations, and in $12(15.0 \pm 4.0 \%)-(7-17.5 \pm 6.0 \%$, and $5-12.5 \pm 6.0 \%$, respectively) due to sexual dysfunction.

Thus, the largest share of complaints affecting the quality of life in the remote postoperative period is due to dysuric phenomena $-27(33.8 \pm 5.0 \%)$, and in half of 
them $(13-16.3 \pm 4.0 \%)$ a combination of dysuric, sexual disorders and gastrointestinal disorders (flatulence, bowel problems, etc.). Clinical manifestations of urinary incontinence were observed on the background of a negative cough test in almost two thirds of patients $(19-63.3 \pm 9.0 \%)$, combined with pollakiuria, nocturia, urgency, exacerbated by alcohol, accompanied by cystalgia. A quality of life survey in $23(57.5 \pm 9.0 \%)$ patients after vaginal hysterectomy and $25-62.5 \pm 9.0 \%$ after abdominal hysterectomy revealed the full effectiveness of surgical recovery and improvement of quality of life one year after surgery. In $15(37.5 \pm 8.0 \%)$ patients of the main group and $12-30.0 \pm 8.0 \%$ of the comparison group there was an improvement, but at the same time dissatisfaction with the quality of life: in $10-12.5 \pm 4.0 \%$ $(6-15.0 \pm 6.0 \%$, and $4-10,0 \pm 5.0 \%$, respectively $)$ due to apical prolapse, in $27-33.8 \pm 5.0 \%(15-37.5 \pm 8.0 \%$, and $12-30.0 \pm 7.0 \%$, respectively) - due to the accession of dysuric manifestations, and in $12(15.0 \pm 4.0 \%)-$ ( $7-17.5 \pm 6.0 \%$, and $5-12.5 \pm 5.0 \%$, respectively) due to sexual dysfunction.

Thus, the largest share of complaints affecting the quality of life in the remote postoperative period is due to dysuric phenomena $-27(33.8 \pm 5.0 \%)$, and in half of them $(13-16.3 \pm 4.0 \%)$ a combination of dysuric, sexual disorders and gastrointestinal disorders (flatulence, stool problems, etc.). Clinical manifestations of urinary incontinence were observed on the background of a negative cough test in almost two thirds of patients $(19-63.3 \pm 9.0 \%)$, combined with pollakiuria, nocturia, urgency, exacerbated by alcohol, accompanied by cystalgia. In the remote postoperative period, the leading symptoms of urogenital syndrome were the appearance of abnormal discharge, dryness and itching of the vagina $(26-65.0 \pm 8.0 \%$, $p<0.05$ and $28-70.0 \pm 7.0 \%, p<0.05$, respectively), the frequency of which was higher than in the control group $(7-23.3 \pm 6.0 \%)$. The results show that Barlow-scale vulvovaginal atrophy was higher in patients with vaginal hysterectomy, and was directly correlated with the age of the patients, where the severity of vulvovaginal atrophy was most significant in women aged $>45$ years, which confirms the role of hypoestrogenism in the mechanisms of trophic changes of the mucosa. Loss of this protective mechanism makes the vaginal epithelium vulnerable to infection and ulcers, which in turn reduces a woman's sexual confidence and contributes to the development of dyspareunia. The majority of patients $(17-42.5 \pm 8.0 \%$ and $21-52.5 \pm 8.0 \%$, respectively) rated their condition on the D. Barlow scale in 2-3 points, i.e. noted discomfort that worsens daily life, and other disorders of moderate severity, to the group with an average degree of $11-27.5 \pm 7.0 \%$ and $13-32.5 \pm 8.0 \%$, respectively, $6-15.0 \pm 6.0 \%$ and $4-10.0 \pm 5.0 \%$, respectively, operated women noted significant violations.

Against the background of estrogen deficiency there are not only atrophic changes of the vaginal mucosa, vulva and urethra, but also changes in the metabolism and quality of collagen types I and III, elastin, their destructuring, resulting in the vagina losing its folds, decreases the depth and lumen of the vaginal canal, develops swelling walls of the vagina. Decreased volume of the submucosal vascular network, ischemia of the vaginal wall and, as a consequence, reduced transudation provoke complaints of dryness and burning in the vagina. Insufficient maturation of the epithelium leads to glycogen deficiency, a decrease in the number and elimination of lactobacilli, a shift in the $\mathrm{pH}$ of the vagina to the alkaline side. Suppression of tissue resistance makes them vulnerable to secondary infection, which forms the basis for the infectious-inflammatory process of the vagina and urinary tract. The results of the examination in the remote postoperative period showed a shift in the $\mathrm{pH}$ level of the vaginal mucosa 5.0-6.5 - in the same $23(57.5 \pm 8.0 \%)$ patients after vaginal hysterectomy, and $25-62.5 \pm 8.0 \%$, which confirmed hypoestrogenism.

\section{Discussion of research results}

The obtained results are in agreement with the results of studies of other scientists on the multifactorial etiology of genitourinary syndrome after hysterectomy [3]. This confirmation will allow to determine the algorithm for the diagnosis of latent clinical manifestations of genitourinary syndrome at the preoperative stage to optimize the choice of access, due to surgical treatment. We offer a sequence of tests recommended for use in the preoperative phase. First, screening for initial symptoms does not support urination and pelvic floor failure - analytical evaluation of questionnaires (ICI-SF) and urination diaries. Before the next stage, the assessment of somatic status and careful history should be assessed - age, body mass index, the presence of concomitant extragenital diseases with increased intra-abdominal pressure, childbirth parity, obstetric trauma, data on previous hormonal treatment of uterine fibroids, laboratory and herbal medicines a number of samples (cough test, Valsalva test, pad test). Optimal diagnostic methods include assessment of psychological and neurogenic status.

Study limitations. The results of the analysis reflect the data only of the gynecological department of the "Kyiv Perinatal Center". Because not all patients joined the study after hysterectomy, there may be shifts in the results of the study due to underrepresentation. However, the study has representative and comparable groups.

Prospects for further research. Given that the manifestation of genitourinary syndrome after surgery for uterine fibroids and, consequently, the negative impact on women's quality of life remains underestimated, it is advisable to conduct further research to modify surgical techniques, development of preventive and rehabilitative postoperative measures based on identified stage of predictors of urogenital disorders.

\section{Conclusions}

The analysis of the structure of predictors of genitourinary syndrome development in the postoperative period in women of older reproductive age was performed. It was found that the most common disorders associated with childbirth (birth of large fetuses) $(20-50.0 \pm 8.0 \%$ and $12-30.0 \pm 8.0 \%)$, episiotomies in childbirth $(18-45.0 \pm 8.0 \%$ and $9-22.5 \pm 7.0 \%)$ maternal birth trauma $(22-55.0 \pm 8.0 \%$, and $16-40.0 \pm 8.0 \%)$. It is determined that these factors can be considered as screening in the algorithm of preoperative diagnosis. In the remote postoperative period, a shift in the $\mathrm{pH}$ level of the vaginal mucosa 5.0-6.5 and, accordingly, the elimination of lactobacilli in the vaginal habitat - in 
$23(57.5 \pm 8.0 \%)$ patients after vaginal hysterectomy, and $25-62.5 \pm 8.0 \%$ after abdominal hysterectomy. In the same patients dysuric phenomena were established, which confirmed hypoestrogenism and dystrophic processes in the tissues of the genitourinary organs after hysterectomy.

Thus, it is advisable to take into account the presence of the above predictors and include them in the diagnostic algorithm at the preoperative stage of the examination. This will allow you to choose the optimal surgical access, the use of prolapse prevention techniques, as well as individualize the approach to the postoperative rehabilitation program and will obtain the expected effect of surgical recovery. Improvement and differentiation of operative techniques and postoperative measures for prolapse prevention will be the subject of prospective research.

\section{Conflict of interests}

The authors declare that they have no conflicts of interest.

\section{References}

1. Roos, A.-M., Sultan, A. H., Thakar, R. (2011). Sexual problems in the gynecology clinic: are we making a mountain out of a molehill? International Urogynecology Journal, 23 (2), 145-152. doi: http://doi.org/10.1007/s00192-011-1516-y

2. Lue, T. F., Basson, R., Rosen, R. et. al. (2004). Sexual Medicine. Sexual Dysfunction in Men and Women. 2nd International Consultation on Sexual Dysfunction. Paris: Edition, 991.

3. Lalaian, R. S., Petrov, Iu. A. (2017). Genitourinary syndrome and its pharmacological correction. Sovremennye problemy nauki i obrazovaniia, 2, 21-35.

4. Postman, D. J., Gass, M. L. (2014). Genitourinary syndrome of menopause: new terminology for vulvovaginal atrophy from the International Society for the Study of Women's Sexual Health and the North American Menopause Society. Menopause, 21 (10), 1063-1068. doi: http://doi.org/10.1097/gme.0000000000000329

5. Kuo, Y.-C., Kuo, H.-C. (2011). Potential factors that can be used to differentiate between interstitial cystitis/painful bladder syndrome and bladder oversensitivity in women. International Journal of Clinical Practice, 66 (2), 146-151. doi: http://doi.org/10.1111/j.1742-1241.2011.02767.x

6. The 2017 hormone therapy position statement of The North American Menopause Society (2017). Menopause, 24 (7), 728 753. doi: http://doi.org/10.1097/gme.0000000000000921

7. Robinson, D., Toozs-Hobson, P., Cardozo, L. (2013). The effect of hormones on the lower urinary tract. Menopause International: The Integrated Journal of Postreproductive Health, 19 (4), 155-162. doi: http://doi.org/10.1177/1754045313511398

8. Vaughan, C. P., Markland, A. D. (2020). Urinary Incontinence in Women. Annals of Internal Medicine, 172 (3), ITC17ITC32. doi: http://doi.org/10.7326/aitc202002040

9. Brubaker, L., Richter, H. E., Norton, P. A., Albo, M., Zyczynski, H. M. et. al. (2012). 5-Year Continence Rates, Satisfaction and Adverse Events of Burch Urethropexy and Fascial Sling Surgery for Urinary Incontinence. Journal of Urology, 187 (4), 1324-1330. doi: http://doi.org/10.1016/j.juro.2011.11.087

10. Nappi, R. E., Palacios, S., Panay, N., Particco, M., Krychman, M. L. (2015). Vulvar and vaginal atrophy in four European countries: evidence from the European REVIVE Survey. Climacteric, 19 (2), 188-197. doi: http://doi.org/10.3109/13697137.2015.1107039

Received date 24.11.2020

Accepted date 29.12.2020

Published date 31.03.2021

Olha Proshchenko, PhD, Assistant, Department of Obstetrics and Gynecology No. 1, O. Bogomolets National Medical University, T. Shevchenko blvd., 13, Kyiv, Ukraine, 01601

E-mail: proshchenko777@gmail.com

Iryna Ventskivska, MD, Head of Department, Department of Obstetrics and Gynecology No. 1, O. Bogomolets National Medical University, T. Shevchenko blvd., 13, Kyiv, Ukraine, 01601

E-mail: ventskivska@gmail.com,

Kamuz Natalia, PhD, Obstetrician-Gynecologist, Kyiv Perinatal Center Predslavinska str., 9, Kyiv, Ukraine, 03150

E-mail: nkamuz@gmail.com

Svitlana Markitanyuk, PhD, Obstetrician-Gynecologist, Kyiv Perinatal Center Predslavinska str., 9, Kyiv, Ukraine, 03150

E-mail: sv.markitanyuk@gmail.com 